\title{
Nasal Mucosal Morphology after Altera tion of Air Stream
}

\author{
Abdulsalam Hussein* and Reda Awadalla** \\ *ENT and ** Anatomy Department, Al-Azhar Faculty of Medicine
}

\begin{abstract}
Introduction The nocturnal application of nasal continuous positive airway pressure is used for treatment of sleep apnoea. The study of the histopathological changes that accompany its application is needed for proper evaluation.

Subjects and Methods: Fifteen adult rabbits were used in this study, 14 were the subject of the experiments and one animal used as control. Under combined general and local anaesthesia, ring of skin and epithelium was removed from the left nostril, the margins of the wound were undermined, averted and brought together with mattress sutures, effectively closing the nostril. The animals were sacrified at intervals. The duration of surgical closure of one nostril was four days in 7 animals and three months in 7 others. Strip of bony and cartilaginous septum was removed after marking the closed side with a silk stitch. In each interval 4 animals were used for transmission electron microscope (TEM) and 3 for scanning electron microscope (SEM).

Results: On the side with sealed nostril the number of goblet cells increased, while the number of ciliated cells decreased. In contrast, on the open side of the nose disappearance of the ciliated cells and a transformation of the respiratory epithelium into thickened multilayered squamous epithelium with no goblet cells.
\end{abstract}

\section{Introduction}

The nocturnal application of nasal continuous positive airway pressure (nCPAP) was first described in 1981 by Sullivan et al. Then in 2003 by Lang et al. and recommended for treatment of sleep apnoea. Since then n CPAP has established itself in the therapeutic management of moderate and severe obstructive sleep apnoea syndrome (Hoffstein et al., 1992).

Room air is supplied with a positive pressure to the nose through a nasal mask by means of a blower unit, thus leading to a pneumatic stabilization of the upper respiratory airways. The apnoea phases are thus eliminated, snoring is distinctly reduced and subjective patient complaints, such as daytime somnolence and lack of concentration, are largely overcome (Ripberger \& Pirsig, 1994 and Kelly et al., 2000).

Only continuous therapy is able to prevent severe consecutive cardiopulmonary disorders and to lower mortality rate (He et al., 1988 and Partinen et al., 1988).
Long-term acceptance of the $\mathrm{CPPAP}$ masks by patients ranges from $67.4 \%$ to 89.7\% (Partinen et al., 1988) when nCPAPtherapy is discontinued, the patients' complaints return.

Long-term therapy can; however, be a burden for the patient if various complications develop. Apart from problems related to mask usage (e.g. pressure spots, skin reaction, claustrophobia, and problems with traveling) there have been reports of eye irritation, noise disturbance caused by the nCPAP-blower, headache and tinnitus (Katsantonis et al.,1988). The most frequent and significant side-effect of nCPAPtherapy, with a reported frequency of 20$70 \%$, is irritation of the upper respiratory pathways and in particular of the nasal mucosa (Kuhl et al., 1997). Changes in the mucosa that are causative for the entire spectrum of symptoms are induced by applying cold and dry room air under elevated pressure. Typical complaints that 
can develop over period of a few days include nasal dryness with accompanying rhinitis, rhinopharyngitis, laryngitis, sinusitis, hypertrophy of the nasal conchae, nasal bleeding and an increased rate of infection of the upper airway (Mayer-Brix et al., 1989 and Boyce \& Eccles, 2006). In infections, products of bacteria and mediators released from mucosa have an impact on mucociliary function (Konietzko, 1986). So that mucociliary transport is impaired in patients with recurrent or chronic respiratory infection (Nuutinen et al., 1983; Toremalm, 1984 and Majima et al., 1986). Morphological changes of respiratory mucosa are one important factor. Loss of cilia and ciliated cells, ultrastructural changes of cilia and changes in the composition of the respiratory mucus in various infections have been reported (Reimer et al., 1978 and Afzelius, 1981). Alteration of nasal airflow induces a functional transformation of the mucosa, the extent of which varies and can range from ciliated epithelium with partial loss of cilia, via columnar epithelium without cilia, to squamous epithelium (Camara et al., 2006).

\section{Subjects and Methods:}

This study was carried out in ENT, Anatomy and Clinical Pathology departments at Al-Azhar and Ain Shams Universities in the period from $1 / 2005$ to $1 / 2006$.

Fifteen adult rabbits were used in this study; 14 were the subject of the experiments and one animal used as control. Under combined general and local anaesthesia, a ring of skin and epithelium was removed from the left nostril, the margins of the wound were undermined, averted and brought together with mattress sutures. Seven of the closed nostril animals were sacrified after four days and the rest were sacrified after 3 months. A strip of bony and cartilaginous septum was removed after marking the closed side with a silk stitch. Specimens from 4 animals of each group were used for TEM; specimens of other 3 animals were used for SEM. For
TEM, specimens were cut into small pieces and fixed by immersion in $2.5 \%$ glutaraldehyde for 2 hours at $4^{\circ} \mathrm{C}$. The tissues were postfixed in $1 \%$ osmium tetroxide solution for $90 \mathrm{~min}$ at $4^{\circ} \mathrm{C}$ dehydrated in an ascending grades of ethanol and embedded in epon. Semithin sections were cut at $1 \mu \mathrm{m}$ with an LKB 8800 ultramicrotome and stained with toluidine blue. Ultrathin sections were contrasted with uranylacetate and lead citrate and examined with electron microscope. For SEM; specimens were processed according to Malick et al. (1976) and Lee et al. (2005). Mucosal samples were washed in saline and fixed by immersion in gluteraldhyde for 24 hours, dehydrated by graded series of alcohol, critical point dried with liquid carbon dioxide, coated with gold and examined with SEM. The ultrastructural features were recorded and compared.

\section{Results}

Control animal: The mucous membrane of the septum of the animal not subjected to closure of one nostril showed the expected pseudo-stratified columnar, ciliated epithelium with a mixture of goblet and ciliated cells (Fig. 1). The epithelium varied considerably between adjacent areas in thickness, density of ciliated cells, and surface regularity. Rarely new cilia were observed in the process of formation of basal bodies in the upper portion of the cell (Fig. 2). Another rare finding was that of club-like shaped cilia "homogenous cilia" (Fig. 3).

Experimental animals: Nearby areas varied extremely in each of the specimens examined. So marked was this variation that no consistent differences could be established between the short-term (four-day) and the chronic (three months) specimens.

Findings on the surgically closed side of the nose: presented unevenness of the surface after deprivation of airflow. It seemed as the ciliated surface was being thrown into folds because of the exuberance of the numerous swollen goblet cells. Ciliogenesis (formation of new cilia) was active on the closed side. Basal bodies were 


\section{Abdulsalam Hussein \& Reda Awadalla}

found in the upper portion of cells topped by microvilli (Fig.4). The cytoplasm of these cells tended to be quite dark, with numerous ribosomes.

Another effect of airway closure on the closed side was the increased number of "homogenous cilia". These are cilia that have a club-like appearance. A few of these were sometimes found among normallooking, mature cilia (Fig. 5).

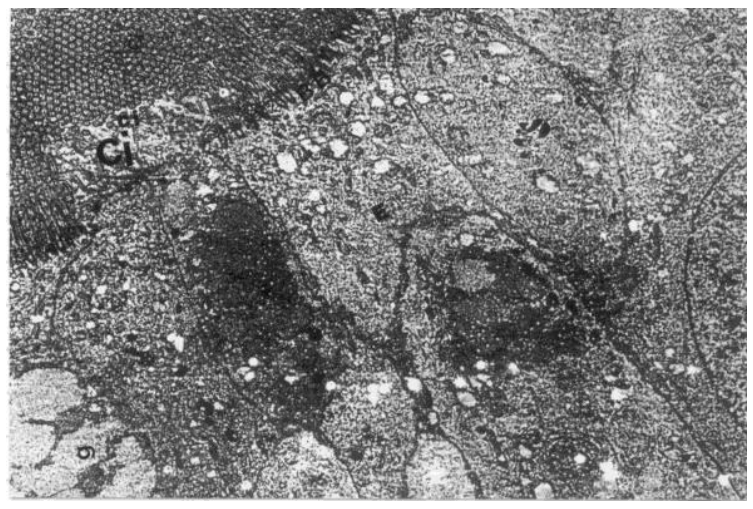

Fig. (1): Transmission electron micrograph of epithelium of nasal septum from control rabbit, showing pseudostratified columnar cells (C) with goblet cells $(\mathrm{G})$ and ciliated surface $(\mathrm{Ci})$. Note basal bodies (BB) appeared in the upper part of cells.

(X 8000).

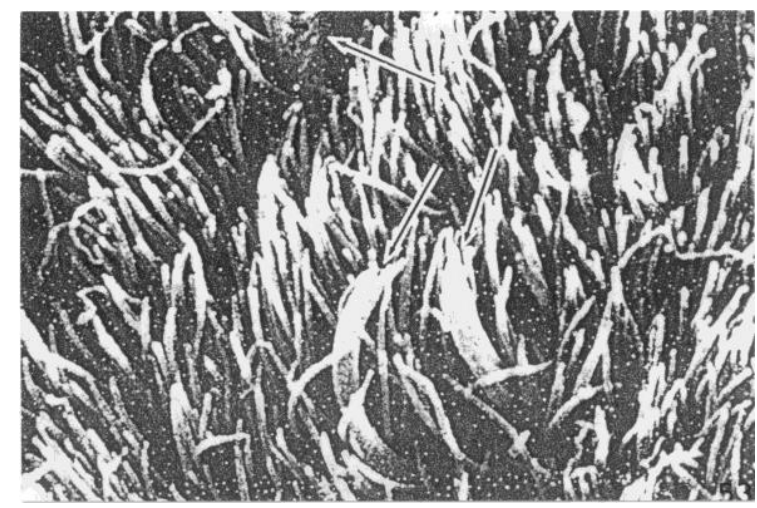

Fig. (3): scanning electron micrograph of epithelial surface of control rabbit, showing several homogenous cilia (arrows) (X 9000)
On the open side of the nose ciliated cells and cilia disappeared in the basal side (Fig. 6) and can range from ciliated epithelium with partial loss of cilia (Fig. 7), via columnar epithelium without cilia to squamous epithelium (Fig.8) without goblet cells. The cell nuclei became irregular and contain varying number of nucleoli (Fig. 7).

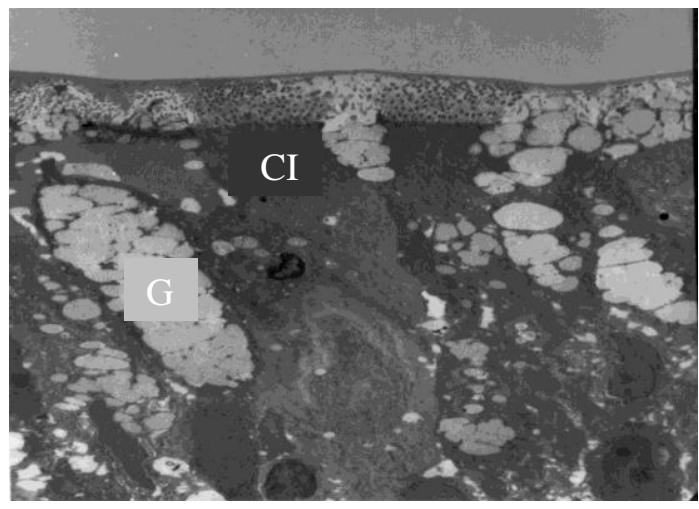

Fig. (2): Transmission electron micrograph of epithelium of nasal septum from control rabbit, showing normal epithelial dark cells (D), goblet cells (G). Note surface of cells covered by cilia (Ci) and basal bodies (BB)appeared in the upper part of cells. (X 10000)

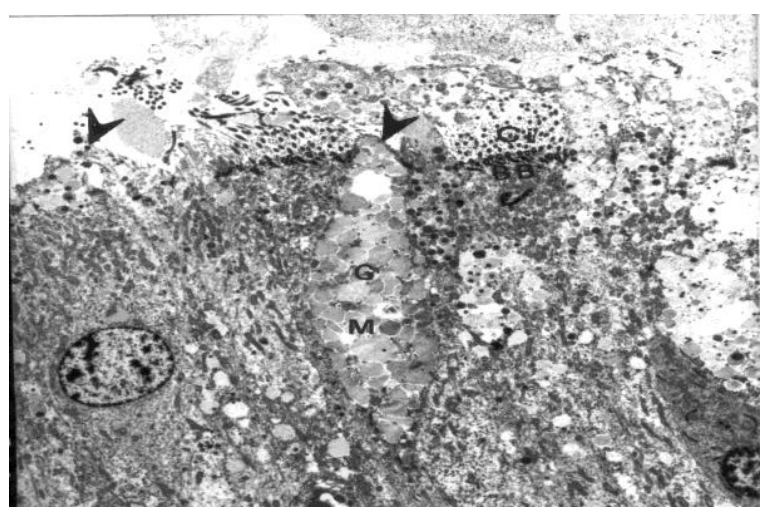

Fig. (4): Transmission EM of respiratory epithelium of nose, showing increased number of goblet cells $(G)$ containing mucus granules (M) many of them are seen discharging their content on the surface. The epithelial surface is uneven showing infoldings by the swollen goblet cells (arrows). The cilia are diminished (Ci), but ciliogenesis is noted by basal bodies in the upper portion of the cells (BB) (X 8000). 


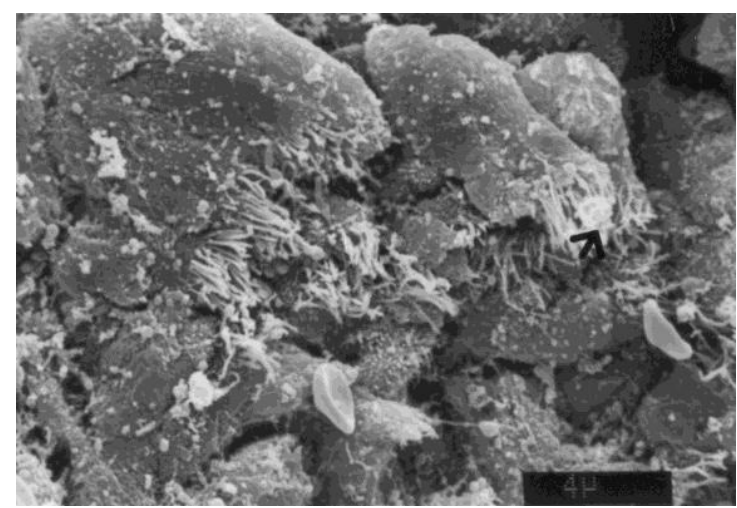

Fig. ( 5): Scanning electron micrograph of epithelium of nasal septum of rabbit after surgical closure of this side of the nose for 3 months, showing several homogenous cilia (arrow) (X 8000)

Fig. (6): Transmission EM of nasal epithelium from opened side of the nose showing epithelial multilayered $(\mathrm{E})$, ciliated surface $(\mathrm{Ci})$ with infoldings, RBCs in lumen (R). No goblet cells are seen.

(X 10000)

Fig. (7): Transmission EM of nasal epithelium showing multilayered cliated epithelium with partial loss of cilia (X 8000)
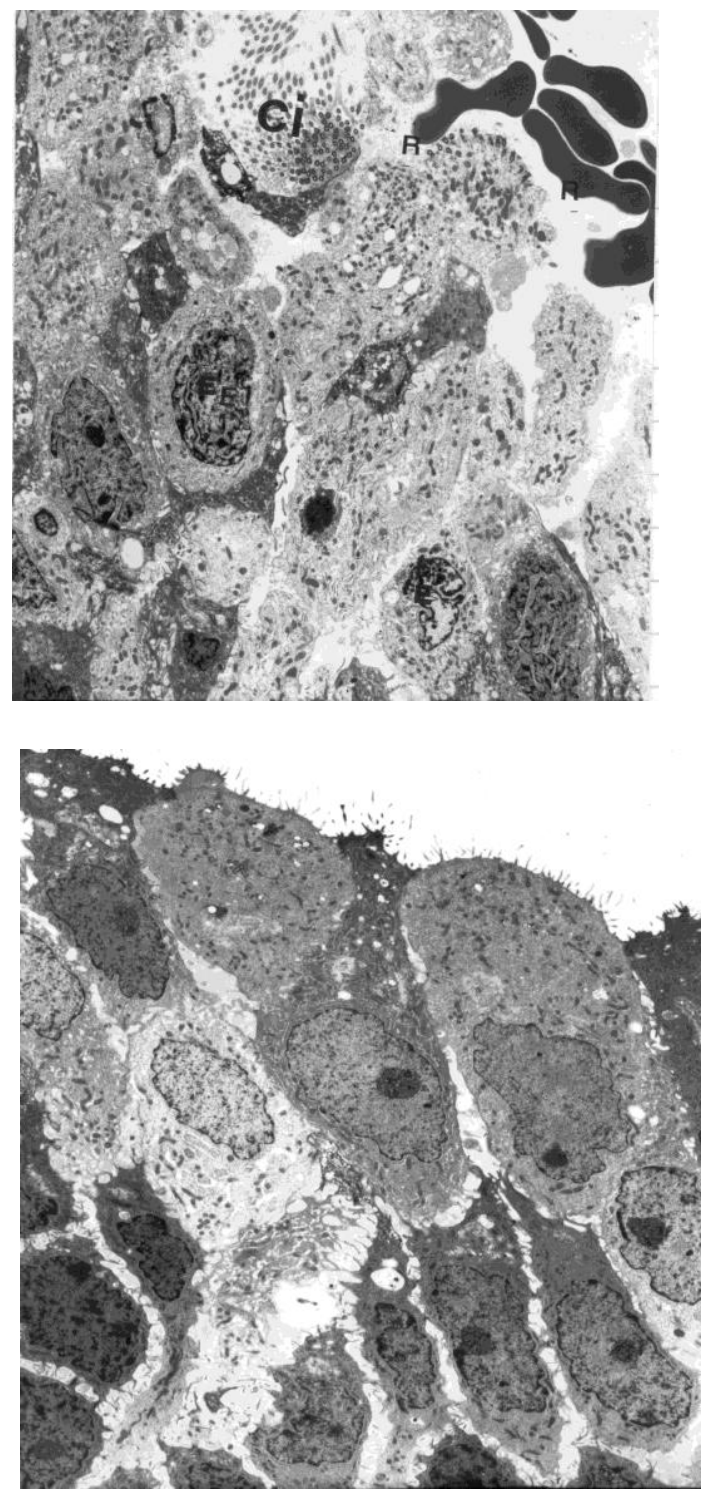


\section{Abdulsalam Hussein \& Reda Awadalla}

Fig. (8): Transmission EM of epithelium from opened side of the nose showing squamous metaplasia (E) loss of goblet cells and loss of cilia basement membrane (BM) (TEM X 8000)

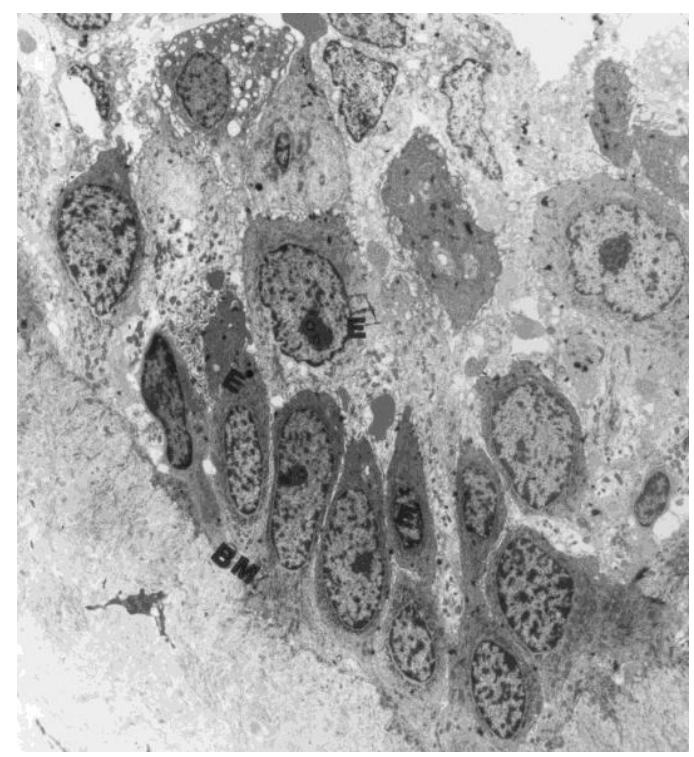

\section{Discussion}

The effect of nasal airflow on the structure and function of the nasal mucosa has been known for many years. Alteration of nasal airflow induces a functional transformation of the mucosa, the extent of which varies and can range from ciliated epithelium with partial loss of cilia, via columnar epithelium without cilia, to squamous epithelium (Jahnke, 1972 and Shin \& Heo, 2005)). The resulting pathophysiological alterations of the mucosa give rise to a variety of rhinological clinical manifestations.

In the present study, sealing the nostril resulted in an increase in the number of goblet cells, while the number of ciliated cells decreased. In contrast, on the open side of the nose, where the air stream had increased due to closure of the contralateral side, the ciliated cells disappeared and the respiratory epithelium was transfomred into a thickened, multilayered squamous epithelium with no goblet cells.

In his pioneer experimental work on rabbits Hilding and Hilding (1970) also demonstrated that the epithelium of the nasal mucosa is transformed into a thick stratified squamous epithelium on the open side of the nose through which the airflow is doubled as compared with normal. On the surgically closed side he also found 3 weeks after the closure, a considerable increase in goblet cells and reduction of ciliated cells. Hilding and Hilding (1970) found pronounced ciliogenesis on the closed side. They concluded that the epithelial types found in the upper respiratory tract are not constant but change under altered external condition.

Tos and Mogensen (1979) reported that after 90 days the epithelium of the closed side was thickened due to hyperplasia of basal cells but it gradually returned to a normal thinner, regular epithelium with increased number of goblet cells starts from the fourth day. However, in our experiment the epithelium did not reach the normal structure. On the patent side, where the airflow was doubled, they found that the cilia were damaged as found in our experiment.

Constantiidis (2000) used nCPAP mask instead of closure nostril and found clumping of microvilli and cilia and modification of epithelial cells with prolongation of mucociliary clearance time 
due to loss of cilia as examined by a saccharine test before and after treatment.

Similar to experimental alteration of nasal airflow is nCPAP-therapy, the acutely developing rhinitis can take a chronic course and can ultimately induce severe alterations of the nasal mucosa, resulting in a disorientation and destruction of cilia as well as epithelial metaplasia (Ohashi \& Nakai, 1983 and Eccles, 2000).

The morphological changes of the nasal epithelium correlate with the functional capacity of the nose and with mucociliary clearance (Toskala et al., 1995).

Boyce and Eccles (2006) found that the continuously elevated nasal airflow influences mucociliary clearance, which in turn is dependent on both ciliary activity and secretory capacity.

The effect of increased airflow and mechanical stimuli can lead to the distruction of cilia and consequently to mucostasis with the corresponding clinical symptoms (Ohashi and Nakai, 1983).

Unilateral occlusion of the nasal vestibule leads to a prolongation of mucociliary clearance on the occluded side of the nose. In contrast, on the non-occluded side, mucociliary clearance is distinctly shortened (Deitmer and Erwing, 1986). If airflow through the nose is completely interrupted on both sides, as, for example, in laryngectomized patients with a tracheostoma, mucociliary clearance of the nose is accelerated (Sakakura et al., 1983 and Constantiidis et al., 2000).

Fisher et al. (1992) comcluded that, mean airflow changes have effects on nasal mucosal structure and function, and our studies suggest that this is a dynamic process which takes time. This is of relevance to the postoperative assessment of patients undergoing surgery to alter the nasal airway.

\section{References}

1. Afzelius BA (1981): Immotile cilia syndrome and ciliary abnormalities induced by infection and injury. Am Rev Dis., 124: 107-9.
2. Boyce $\mathbf{J}$ and Eccles $\mathbf{R}$ (2006): Do chronich changes in nasal airflow have any physiological or pathological effect on the nose. J. Clinic. Otolaryng., 31-35.

3. Camara J,Garrosa M, Gayoso M (2006) : Histological changes in rat nasal epithelia after unilateral neonatal naris occlusion. J. Microscopy Research and Technique., 69: 585-594.

4. Constantinidis J, Knobber D, Steinhart $H$, Kuhn $J$ and Iro $H$ (2000): Fine structural investigation of the effect of nCPAP mask application on the nasal mucosa. J Acta Otolaryngologica ., 129 (31): 432-437.

5. Deitmer T, and Erwing $H$ (1986): The influence of nasal obstruction on mucociliary transport. Rhinology ., 24: 15962.

6. Eccles R (2000) : Nasal airflow in health and dise-ase. Acta Otoalryngol., 120: 580595.

7. Fisher E, Lund V, and Rutman A (1992): Human nasal mucosa after deprivation of airflow. J. Rhinology ., 30: 5-10.

8. He J, Kryger MH, Zovick FJ, Conway W, and Roth T (1988) : Mortality and apnoea index in obstructive sleep apnoea: Experience in 385 male patients. Chest., 94:9-4.

9. Hilding DA, and Hilding AC (1970): Electron microscopic observation of nasal epithelium after experimental alteration of airflow. Ann Otol Rhinol Layrngol., 79: 451-60.

10. Hoffstein V, Viner S, Mateika S, and Conway J (1992): Treatment of obstructive sleep apnoea with nasal continuous airway pressure-patient compliance, perception of benefits and side effects. Am Rev Respir Dis ., 145: 841-5.

11. Jahnke V (1972) : Ultrastruktur der normalen Nasenschleimhaut des menschen. Laryngo Rhino Otol ., 51: 30-41.

12. Katsantonis GP, Schweitzer PK, Branham GH, Chambers G, and Walsh JK (1988) : Management of obstructive sleep apnoea: comparison of various treatment modalities. Laryngoscope., 98: 304-9.

13. Kelly JT, Prasad AK and Wexler AS ( 2000) : Detailed flow patterns in the nasal cavity. J. Appl. Physiol ., 323-337.

14. Konietzko N (1986) : Mucus transport and inflammation. Eur. J. Respir. Dis., 69 (suppl 147): 72-79.

15. Kuhl S, Hollandt JH, and Siergert $\mathbf{R}$ (1997): Therapie mit nasalem CPAP 


\section{Abdulsalam Hussein \& Reda Awadalla}

(continuous positive airway pressure) bei patienten mit obstruktiven schlafapnoe syndrome (OSAS). Teil II: Nebenwirkungen der nCPAP-therapie. Einflu auf die langzata-kzeptanz. Laryngo Rhino Otol ., 76: 608-13.

16. Lang C, Grutzenmacher S, and Milynski B (2003) : Investigating the nasal cycle using endoscopy, Rhinoresistometry and Acoustic Rhinometry. Laryngoscopoy., 113: 284-289.

17. Lee CH, Lee SS, Mo JH, and Kim IS (2005) : Comparison of ciliary wave disorders measured by image analysis and electron microscopy. J. Acta. OtoLaryngologica ., 125: 571-576.

18. Majima Y, Sakakura Y, Matusbara T, and Miycshi Y (1986) : Possible mechanism of reduction of nasal mucociliary clearance in chronic infections. Clin Otolaryngol ., 11: 55-60.

19. Malick L, Wilson RB, and Stetson D (1976): Modified thiocarbo hydrazide procedure for scanning electron microscopy: routing use for normal pathological and experimental tissue. Scie Tech ., 50: 265-9.

20. Mayer-Brix J, Becker H, and Peter JH (1989): Nasale vberdruckbeatmung bei ostruktivem schlaf-Apnoesyndrom, thgeoretische und praktische halsnasenohrenarztliche aspe-kte. Laryngo Rhino Otol ., 68: 295-8.

21. Nuutinen J, Karja J, and Karjalainen $\mathbf{P}$ (1983) : Measurement of impaired mucociliary activity in children. Eur. J. Respir Dis ., 64 (Suppl 128): 454-6.

22. Ohashi Y, and Nakai Y (1983): Functional and morphological pathology of chronic sinusitis mucous membrane. Acta Otolaryngol (Stockh) ., 397: 11-48.

23. Ohashi Y, and Nakai Y (1983): Reduced ciliary action in chronic sinusitis. Acta Otolaryngol (Stockh) ., 396: 3-9.

24. Partinen M, Jamieson A, and Guilleminault C (1988) : Long-term outcome for obstructive sleep apnoea syndrome, patients mortality Chest ., 94: 1200-4.

25. Reimer A Von Mecklenburg C, and Toremalm NG (1978): The mucociliary activity of the upper respiratory tract. A functional and morphological study on human and animal material with special reference to maxillary sinus disease. Acta Otolaryngol (Stock) ., Suppl 355: 1-20.

26. Ripberger R, and Pirsig W ( 1997): Die nasale vberdruckbeatmug (nCPAP) zur therapie der obstruktiven schlafapnoe: Akzeptanz bei 50 patienten. Laryngo Rhino Otol ., 73: 581-5.

27. Sakakura Y, Vkai K, Majima Y, Murai S, Harada T, and Miyoshi Y (1983): Nasal mucociliary clearance under various conditions. Acta Otoalryngol (Stockh) ., 96: 167-73.

28. Shin SH and Heo WW (2005) : Effects of unilateral naris closure on the nasal and maxillary sinus mucosa in rabbit. J Auris Nasus Larynx ., 32 (2): 139-43.

29. Sullivan CE, Issa FG, Berthon-Jones L, and Eves $L$ (1981): Reversal of obstructive sleep apnoea by continuous positive airway pressure applied through the naris. Lancet ., 1: 862-5.

30. Toremalm NG (1984): Mucociliary function in chronic infections. Rhinology., 22: 111-3.

31. Tos M, Mogensen C (1979): Experimental surgery of the nose, changes of the epithelium in the vestibular region at altered airflow.Acta Otolaryngol (Stockh) ., 87: 317-23.

32. Toskala E, Nuutinen J, Rautiainen M, and Torkkeli T (1995): The correlation of mucociliary transport and scanning electron microscopy of nasal mucosa. Acta Otolaryngol (Stockh) ., 115: 61-5. 


\section{التغير التركيبى لمخاطية الأنف بعد تغيير شدة تيار الهواء المار

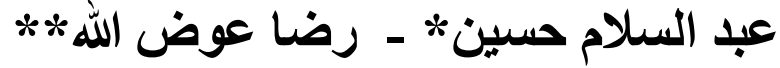

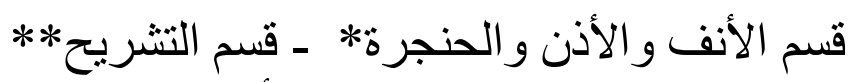$$
\text { كلية الطب - جامعة الأزهرة }
$$

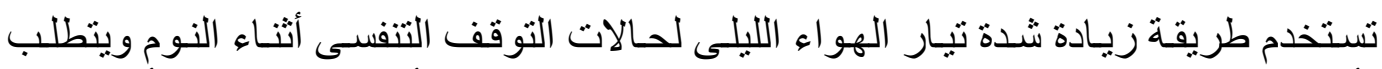

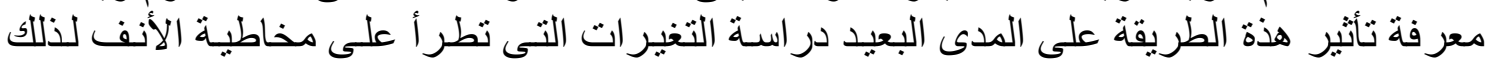

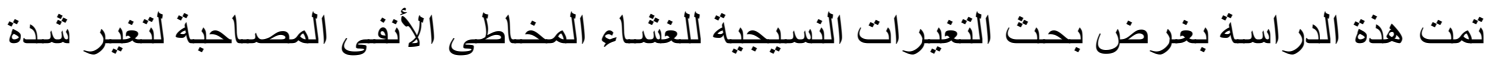

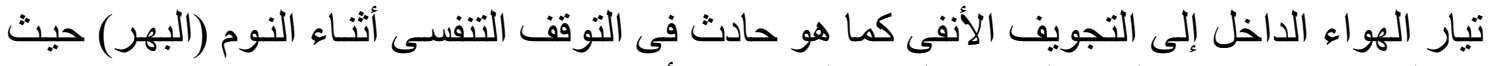

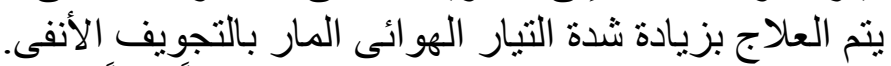

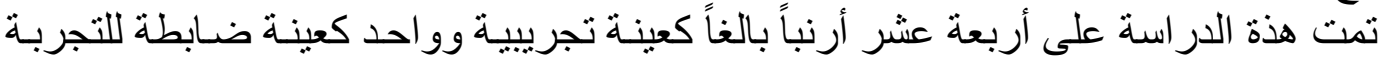

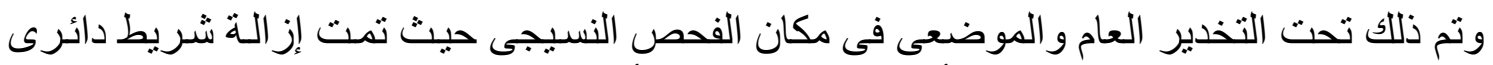
حلى من الغشاء المخاطى للجزء الأيسر من التجويف الأنفى ثم خياطة طرفى الثقى الجر النى الثى لغلق

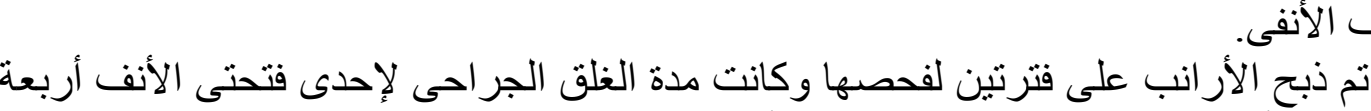

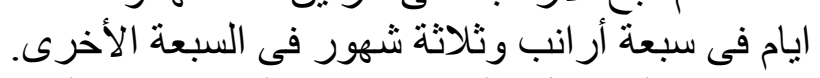

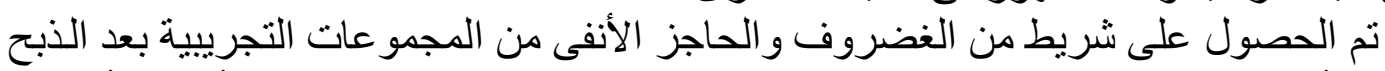

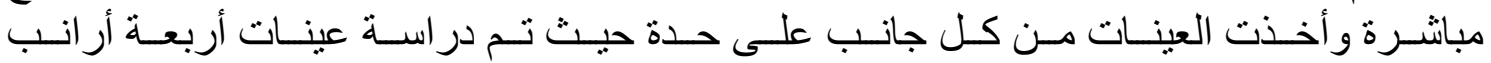

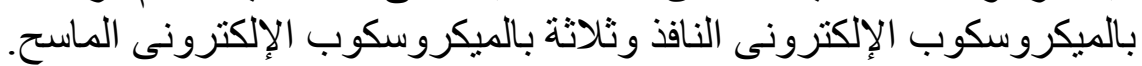

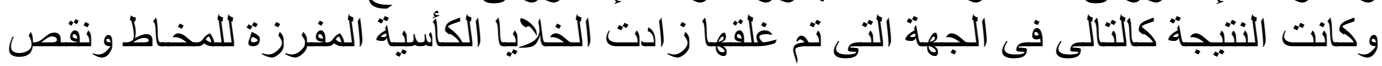

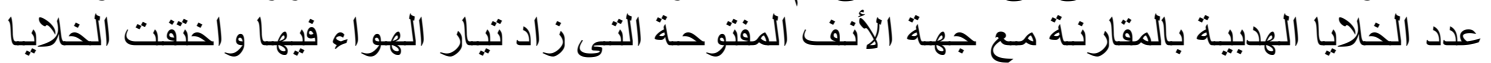
الهدبية وتحول النسيج الأنفى العادى إلى نسيج طبقى حرشفى سميك مع زيادة الخيار الخلايا الكاسية. 